\title{
Short-Course Antibiotic Treatment Is Not Inferior to a Long-Course One in Acute Cholangitis: A Systematic Review
}

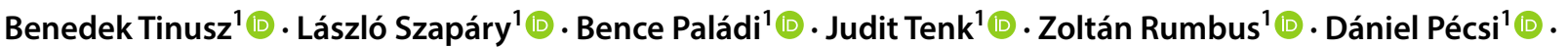

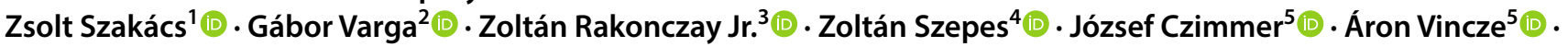 \\ Péter Hegyi ${ }^{1}$ (1) $\cdot$ Bálint Eröss ${ }^{1}$ (i)
}

Received: 1 August 2018 / Accepted: 8 October 2018 / Published online: 27 October 2018

(c) The Author(s) 2018

\begin{abstract}
Aims Our aim was to summarize the available literature on the effect of short- versus long-course antibiotic therapy on acute cholangitis.

Methods A systematic review was performed according to the PRISMA Statement. We searched three databases for papers discussing the length of ABT in acute cholangitis. Long and short therapy groups were defined based on the most recent guideline available at the time of publication of the articles. Primary outcomes were the rate of recurrent cholangitis and mortality; secondary outcomes included length of hospitalization and the duration of fever after ERCP. Data were extracted on these outcomes and on general characteristics. A narrative synthesis was then provided based on collected data.

Results Out of 692 articles produced by our search, four met our inclusion and exclusion criteria. These contained 205 acute cholangitis patients, with 137 and 68 patients receiving short and long antibiotic therapy, respectively. No significant difference was observed in any of the studies on the outcomes of mortality and duration of fever after ERCP between the two groups. One out of four studies found the rate of recurrent cholangitis to be significantly lower in the short antibiotic therapy group $(0.0 \%$ vs. $13.3 \%, p=0.036)$. Length of hospitalization was only compared in the same retrospective article, where it was found to be significantly shorter in the short-term antibiotic therapy group (with a median of $14 \mathrm{vs.} 17.5$ days, $p<0.001$ ). Conclusions Our review suggests short-course antibiotic therapy is non-inferior to long-course treatment; however, several limitations underline the need for well-designed randomized trials.
\end{abstract}

Keywords Cholangitis $\cdot$ Antibiotic $\cdot$ Antimicrobial $\cdot$ Antimicrobial treatment $\cdot$ Length of treatment

$\begin{array}{ll}\text { Abbreviations } \\ \text { ABT } & \begin{array}{l}\text { Antibiotic treatment } \\ \text { Endoscopic retrograde } \\ \text { ERCP }\end{array} \\ \text { cholangiopancreatography } \\ \text { LOH } & \begin{array}{l}\text { Length of hospitalization } \\ \text { NOS }\end{array} \\ \text { Newcastle-Ottawa Scale } \\ \text { PRISMA-P } & \begin{array}{l}\text { Preferred Reporting Items for Systematic } \\ \text { Review and Meta-Analysis Protocols }\end{array} \\ \text { RCT } & \text { Randomized controlled trial }\end{array}$

Electronic supplementary material The online version of this article (https://doi.org/10.1007/s10620-018-5327-6) contains supplementary material, which is available to authorized users.

Bálint Erőss

eross.balint@pte.hu

Extended author information available on the last page of the article

\section{Introduction}

Acute cholangitis is a bacterial infection of the bile ducts that can be life-threatening if not diagnosed and treated in time [1].

The most up-to-date and widely used guidelines on the subject are the 2018 Tokyo Guidelines. A separate subarticle of these guidelines specifically deals with the topic of antimicrobial treatment for acute cholangitis [2]. The previous versions of the Tokyo Guidelines were published in 2007 and 2013 [3, 4].

According to guidelines provided by the European Society of Gastrointestinal Endoscopy (ESGE) and the American Society of Gastrointestinal Endoscopy (ASGE) as well as the 2018 Tokyo Guidelines, the general treatment of the disease should involve a source control procedure along with antibiotic therapy $[5,6]$. To control the source of infection, drainage of biliary tract is necessary with either endoscopic 
or percutaneous transhepatic biliary drainage in grade II or III acute cholangitis [3]. Antimicrobial therapy is also recommended in all cases of acute cholangitis [2]. Mortality ranges between 5 and $10 \%$, depending on comorbidities, the modality of treatment applied, and the severity grade of the disease [7].

$\mathrm{ABT}$ enables the usage of elective drainage procedures rather than urgent ones [8]. The 2018 Tokyo Guidelines provide a description of the specimen that should be obtained to identify the microorganisms causing the infection (bile cultures as the first choice), the antimicrobial agents to prescribe in each severity grade of the disease, and the optimal route and duration of administration. The guidelines recommend 4-7 days of treatment once the source of infection is controlled, regardless of severity. If bacteremia with Gram-positive cocci is present, antibiotic therapy should be administered for at least two weeks for the prevention of infective endocarditis [2]. The guidelines describe these previous recommendations on the length of antimicrobial therapy as strong; however, the quality of evidence is based on expert opinion and thus remains low.

The importance of the duration of antibiotic therapy (ABT) in cholangitis does not only originate from obvious financial reasons, but also from the multiple harmful effects of the (potentially) unnecessarily long ABT as well.

The aim of this study was to systematically review the literature currently available on the length of antibiotic therapy in acute cholangitis to evaluate if short-course ABT is noninferior to long-course $\mathrm{ABT}$ for the treatment of the disease.

\section{Materials and Methods}

Our systematic review was conducted in accordance with the Preferred Reporting Items for Systematic Reviews and Meta-Analysis (PRISMA) Statement [9]. The protocol was registered at PROSPERO on January 26, 2018, under registration number CRD42018083638.

\section{Search}

A comprehensive search was carried out by two independent authors using three databases (PubMed, EMBASE, and the Cochrane Library). The aim was to gather relevant articles on the topic of ABT in patients with acute cholangitis from inception up to November 11, 2017.

The PICO items were the following: We included studies that examined patients with acute cholangitis diagnosed according to the most recent guidelines available at the time $(\mathrm{P})$, with at least one group of acute cholangitis patients that were treated with antibiotic therapy for a short duration. A short-course ABT was defined as treatment with antibiotics for a shorter duration than that is suggested by the available protocol or guideline at the publication date of the study (I). We imposed no restriction in terms of the etiology of cholangitis. We had no strict requirement for a control group as that criterion would have narrowed the number of articles included even further; when available, we considered the group of patients who received the traditional, long course of ABT as a control group. Long-course ABT was defined as treatment with antibiotics for the traditional length of time (or more) as suggested by the then available guideline (C). In terms of outcomes, we considered the rate of recurrent cholangitis and mortality as our primary outcomes and the length of hospitalization $(\mathrm{LOH})$ and duration of fever after the ERCP procedure as secondary outcomes $(\mathrm{O})$.

We used the following query in all three databases: "Cholangitis AND (Antibiotic OR Antimicrobial) AND (Duration OR Length OR Stop OR Cessation OR Discontinuation)." For a draft of our search strategy, see Supplementary File 1: Our search strategy.

We limited our search to human and English language studies via the appropriate filters when searching in PubMed and EMBASE. The Trials filter was applied when searching for articles in the Cochrane Library. To expand the search, we performed a recursive hand search on the references of relevant articles.

We also searched PROSPERO, an international database for systematic reviews and meta-analyses, for previously completed reviews on the subject.

\section{Inclusion and Exclusion Criteria}

We excluded the following types of publications: letters, comments, case reports, case studies, conference abstracts, editorials, and reviews.

In our review, we included both observational (cohort, cross-sectional cohort, and case-control) and interventional (randomized and non-randomized, controlled and non-controlled) trials and studies. We included studies with both prospective data collection and retrospective data collection, regardless of their primary objectives. If there were multiple publications on the same group of patients, the latest was always chosen.

\section{Screening and Selection}

After the initial search, all results were imported into a reference management program (EndNote X7, Clarivate Analytics, Philadelphia, PA, USA). The software was used in the process of removing duplicates by searching for articles with overlapping publication year, author, and/or title.

After duplicates were removed, the authors screened the remaining articles against the pre-defined eligibility criteria 
by title, abstract, and then full text. Two different researchers conducted each step simultaneously. Any disagreements were resolved by consensus.

\section{Data Extraction}

Numerical data were extracted by two investigators and manually entered on an Excel 2016 sheet (Office 365, Microsoft, Redmond, WA, USA). Data were collected on the first author, year of publication, study design, geographical location, number of patients, and basic demographics (age and sex ratio) in each group. Data were extracted on the definition of the groups and the length of ABT in each. Finally, data were collected on the four outcomes of interest noted previously.

\section{Quality Assessment and Quality of Evidence}

A modified version of the Newcastle-Ottawa Scale (NOS) was used to assess the quality of cohort studies included in the analysis [10]. Supplementary File 2 shows the NOS Quality Assessment Form for Cohort Studies modified to fit the study design of the articles included. The Cochrane Risk of Bias Tool was used to assess the quality of the RCT included [11]. We used the Grading of Recommendations Assessment, Development and Evaluation (GRADE) methodology to rate the quality of evidence as high (level A), moderate (level B), low (level C), or very low (level D). The strength of recommendations was also graded according to the same guidelines as strong (1) or weak (2) [12].

\section{Results}

\section{Study Selection}

Our search yielded a total of 692 articles, 101 in PubMed, 566 in EMBASE, and 25 in the Cochrane Library. After removing duplicates and checking the titles and abstracts against the eligibility criteria, six articles were assessed by full text and, finally, four were deemed eligible for systematic review [13-16]. The reason for discarding the last two studies was that they did not include a separately analyzed subgroup of patients with short ABT [17], or the patients were treated with short-course ABT, but only a fraction of them had acute cholangitis (and no subgroup analysis was performed) [18]. Two out of the four eligible studies were prospective [14, 15] and two were retrospective [13, 16]. These included a total of 205 acute cholangitis patients with 137 and 68 of them receiving short- and long-course ABT, respectively (Fig. 1). Collected data and the characteristics of the studies included are shown in Tables 1 and 2.

\section{Rate of Recurrent Cholangitis}

All of the four articles [13-16] assessed the rate of recurrent cholangitis during the follow-up and were included in the systematic review. In van Lent et al., $23.7 \%(n=19)$ of all the patients $(n=80)$ developed recurrent cholangitis, with $26.8 \%(n=11)$ in the short ABT group (ABT for three or fewer days), $21.1 \%(n=4)$ in the medium-length ABT group (ABT for $4-5$ days), and $20.0 \%(n=4)$ in the long ABT group (ABT for more than five days). The $p$ value (0.8) showed no statistically significant difference across groups [13]. In Kogure et al. and Limmathurotsakul et al., none of the 34 patients examined in these studies had a recurrent episode of cholangitis during their follow-up period [14, 15]. In Uno et al., the recurrence rate was $4.4 \%(n=4)$ in 91 patients, with $0.0 \%(n=0)$ and $13.3 \%(n=4)$ in the short and long ABT groups, respectively. This difference appeared to be significant $(p=0.036)$ [16].

\section{Mortality}

All of the four articles included [13-16] assessed mortality. Van Lent et al. reported a $11.3 \%(n=9)$ overall mortality among the patients included, with 14.6, 10.5, and 5\% $(n=6,2,1)$ in the short, medium, and long ABT groups, respectively. This difference between groups did not prove to be significant [13]. In both Kogure et al. and Limmathurotsakul et al., there were no deaths registered among the 34 patients included in total [14, 15]. In Uno et al., two deaths were observed among the 91 patients $(2.2 \%)$, both of which occurred in the long ABT group, accounting for a $5.7 \%$ mortality in this group, with no significant difference between the short and long ABT groups $(p=0.179)$ [16].

\section{Length of Hospital Stay}

LOH was only assessed in one study. Uno et al. [16] reported a 14-day median $\mathrm{LOH}$ (IQR: 10.0-17.0 days) for the short ABT group and a 17.5-day median LOH (IQR: 16-22.5 days) in the long ABT group with a significant difference in between $(p<0.001)$.

\section{Duration of Fever Following ERCP}

Three out of the four articles included data on the duration of fever after the ERCP procedure. Van Lent et al. only reported a median of one day of fever (range 0-17 days) duration after ERCP for all patients in the study [13]. Kogure et al. found the median duration of fever to be two days across all 
Fig. 1 PRISMA flowchart for the study selection process. From: Moher D, Liberati A, Tetzlaff J, Altman DG, The PRISMA Group (2009) Preferred Reporting Items for Systematic Reviews and Meta-Analysis: The PRISMA Statement. PLoS Med 6(6):e1000097. https://doi. org/10.1371/journal.pmed1 000097. For more information, visit http://www.prisma-state ment.org
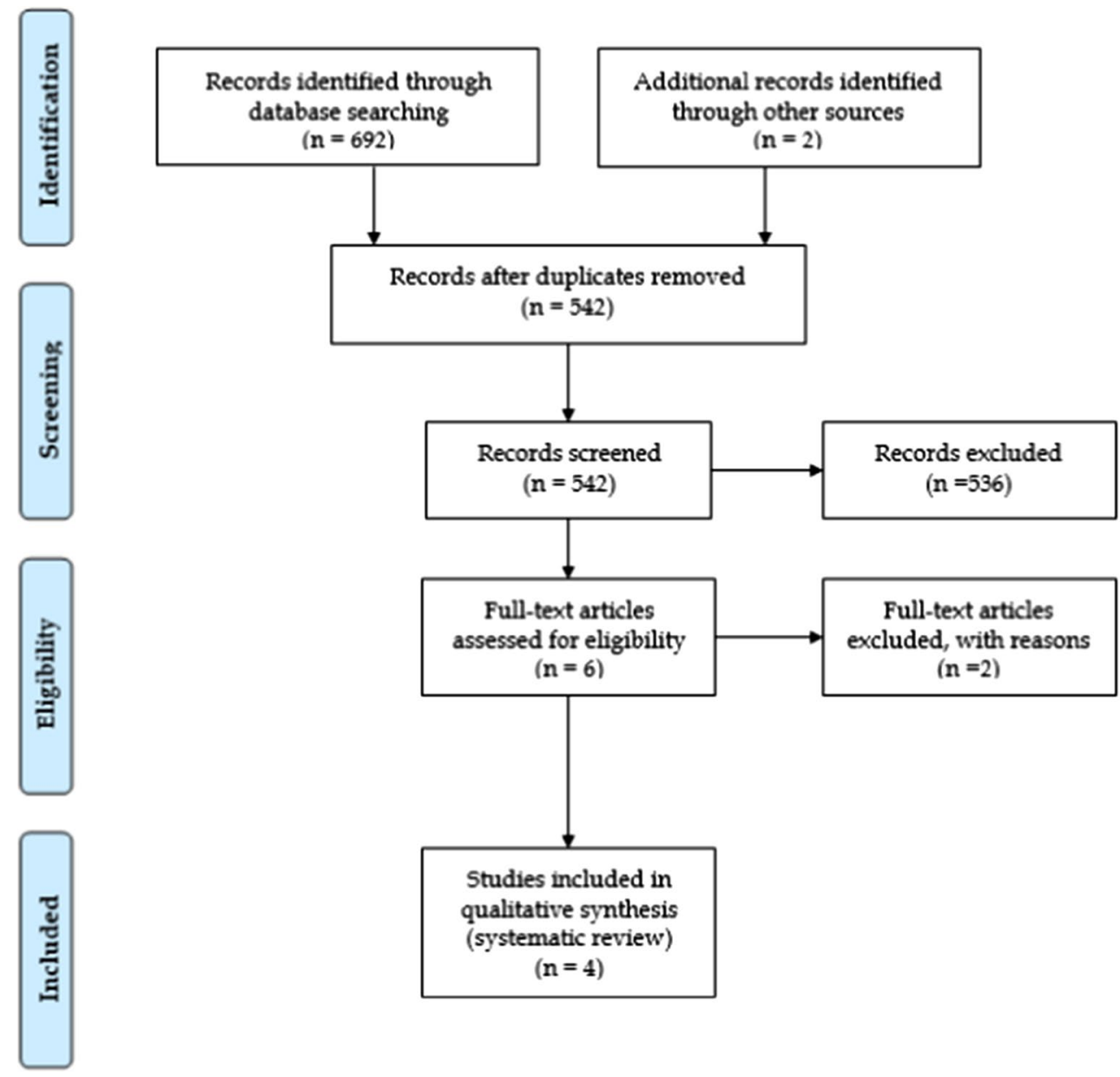

patients included [14]. Limmathurotsakul et al. reported the duration to be $1.8 \mathrm{~h}$ (SD 1.8) in the short ABT group and $1.2 \mathrm{~h}$ (SD 0.7) in the long ABT group. The authors of this study found no significant difference between the two groups in terms of fever duration $(p=0.467)$ [15].

\section{Discussion}

To date, no meta-analysis or separate systematic review has been published on the subject of the duration of antibiotic therapy in acute cholangitis. We aimed to summarize the available literature on the topic by systematically reviewing articles that compare long- and short-course ABT in acute cholangitis.

There is evidence that prolonged ABT increases the risk of antibiotic resistance in microorganisms; however, there is no clear correlation between early cessation of antibiotic therapy and an increased chance of resistance [19]. A recent meta-analysis showed that longer ABT duration and multiple courses are associated with higher rates of resistance in respiratory and urinary tract infections [20]. Moreover, in the case of orally administered antibiotics, the risk of
Clostridium difficile colitis is also an issue clinicians must be aware of. Another meta-analysis lists cephalosporins as one of the main causes of Clostridium difficile infections [21]. As stated previously, this group of antibiotics is recommended for the baseline therapy of acute cholangitis in all severity grades [2]. Furthermore, longer ABT duration is associated with longer hospital stay [16], thus leaving the patients at risk of the many, well-documented complications of prolonged hospitalization, such as pneumonia, venous thromboembolism, and muscle loss [22, 23], which especially affect the elderly [23].

A recent randomized controlled trial (RCT) carried out by Sawyer et al. came to the conclusion that a fixed, short (fourday) duration of antimicrobial treatment for intraabdominal infections might be sufficient after a successful source control procedure has been completed. In that study, however, patients presenting with acute cholangitis only accounted for a small percentage of the total population [18]. The high mortality rate of acute cholangitis underlines the need for similar studies specifically designed to assess the exact duration of antibiotic treatment in this type of infection.

Van Lent et al. [13] state that the fear of complications of acute cholangitis is what currently drives clinicians to 
Table 1 Characteristics of studies included

\begin{tabular}{|c|c|c|c|c|c|c|c|c|c|}
\hline References & Country & Design & $\begin{array}{l}\text { Patient } \\
\text { number }\end{array}$ & Male $(n)$ & Groups & $\begin{array}{l}\text { ABT length } \\
\text { (days) }\end{array}$ & $\begin{array}{l}\text { Age (years, } \\
\text { mean, SD) }\end{array}$ & $\begin{array}{l}\text { Follow- } \\
\text { up (days, } \\
\text { median) }\end{array}$ & $\begin{array}{l}\text { Outcomes } \\
\text { measured }\end{array}$ \\
\hline \multirow[t]{3}{*}{$\begin{array}{l}\text { van Lent } \\
\text { et al. [13] }\end{array}$} & \multirow[t]{3}{*}{ Netherlands } & \multirow[t]{3}{*}{$\begin{array}{l}\text { Retrospective } \\
\text { case-con- } \\
\text { trol }\end{array}$} & 41 & Not specified & $\begin{array}{l}\text { G1: ABT for } \\
3 \text { days or } \\
\text { less }\end{array}$ & $\begin{array}{l}\text { Less than } \\
3 \text { days }\end{array}$ & \multirow{3}{*}{$\begin{array}{l}\text { Not speci- } \\
\text { fied, article } \\
\text { states that } \\
\text { groups } \\
\text { are well } \\
\text { matched }\end{array}$} & 71 & \multirow{3}{*}{$\begin{array}{l}\text { Mortality, } \\
\text { recurrent } \\
\text { cholan- } \\
\text { gitis }\end{array}$} \\
\hline & & & 19 & & $\begin{array}{c}\text { G2: ABT for } \\
4-5 \text { days }\end{array}$ & 4-5 days & & 143 & \\
\hline & & & 20 & & $\begin{array}{l}\text { G3: ABT for } \\
\text { more than } \\
5 \text { days }\end{array}$ & $\begin{array}{l}\text { More than } \\
5 \text { days }\end{array}$ & & 181 & \\
\hline $\begin{array}{l}\text { Kogure et al. } \\
{[14]}\end{array}$ & Japan & $\begin{array}{l}\text { Prospective } \\
\text { single arm }\end{array}$ & 18 & 12 & $\begin{array}{l}\text { Short ABT } \\
\text { therapy } \\
\text { group }\end{array}$ & $3^{\mathrm{a}}$ & $73(12)$ & 28 & $\begin{array}{l}\text { Mortality, } \\
\text { recurrent } \\
\text { cholangi- } \\
\text { tis, dura- } \\
\text { tion of } \\
\text { fever after } \\
\text { ERCP }\end{array}$ \\
\hline \multirow[t]{2}{*}{$\begin{array}{l}\text { Limma- } \\
\text { thurotsakul } \\
\text { et al. [15] }\end{array}$} & Thailand & $\begin{array}{l}\text { Randomized } \\
\text { controlled } \\
\text { trial }\end{array}$ & 8 & 5 & $\begin{array}{l}\text { G1: ABT } \\
\text { stopped } \\
\text { after } \\
\text { temperature } \\
\text { below } 37.8 \\
\text { degrees for } \\
72 \mathrm{~h}\end{array}$ & $5^{\mathrm{a}}\left(1.7^{\mathrm{b}}\right)$ & $73.1(15.9)$ & 56 & \multirow[t]{2}{*}{$\begin{array}{l}\text { Mortality, } \\
\text { recurrent } \\
\text { cholangi- } \\
\text { tis, dura- } \\
\text { tion of } \\
\text { fever after } \\
\text { ERCP }\end{array}$} \\
\hline & & & 8 & 5 & $\begin{array}{l}\text { G2: Full } \\
14 \text { days of } \\
\text { ABT }\end{array}$ & $14^{\mathrm{a}}\left(0.0^{\mathrm{b}}\right)$ & $66.5(15.3)$ & 56 & \\
\hline \multirow[t]{2}{*}{$\begin{array}{l}\text { Uno et al. } \\
\text { [16] }\end{array}$} & Japan & $\begin{array}{l}\text { Retrospective } \\
\text { cohort }\end{array}$ & 51 & 35 & $\begin{array}{l}\text { G1: less than } \\
2 \text { weeks of } \\
\text { ABT }\end{array}$ & $10^{\mathrm{a}}$ & $76(11.1)$ & 56 & \multirow{2}{*}{$\begin{array}{l}\text { Mortality, } \\
\text { recurrent } \\
\text { cholangi- } \\
\text { tis, length } \\
\text { of hospi- } \\
\text { talization }\end{array}$} \\
\hline & & & 40 & 23 & $\begin{array}{l}\text { G2: more } \\
\text { than } \\
2 \text { weeks of } \\
\text { ABT }\end{array}$ & $14.5^{\mathrm{a}}$ & 81.7 (7.95) & 56 & \\
\hline
\end{tabular}

${ }^{\mathrm{a}}$ Mean

${ }^{\mathrm{b}}$ Standard deviation

prescribe antibiotics for longer periods of time. However, their results suggest that there is no significant difference between short-course $\mathrm{ABT}$ and long-course $\mathrm{ABT}$ in terms of complications, at least in the case of complete biliary drainage. Without achieving biliary drainage, the risk of a hepatic abscess increases due to the continuously elevated pressure in the infected bile ducts [24]. On the other hand, if the intervention is successful, complications mostly occur shortly after the endoscopic procedure [25, 26], with the exception of recurrent cholangitis, which is reported to develop at a median time of 18 weeks after the drainage and can be observed in $14 \%$ of patients [27]. Observation of this length was only conducted in one out of the four articles included [13].

The total recurrence and mortality rates $(23.7 \%$ and $7.2 \%$, respectively) were extraordinarily high in van Lent et al. compared to all the others [13]. This is likely a result of the high ratio of acute cholangitis patients with malignancy as an etiological factor (36 patients out of 80 , $45 \%$ ). Moreover, the number of patients with the previous stent placement was also high in this study (50 patients out of $80,62.5 \%$ ), which may also have contributed to the high recurrence and mortality reported. Excluding van Lent et al., the recurrence and mortality rate varied between $0-4.4$ and $0-2.2 \%$, respectively.

Kogure et al. hypothesize that a fever-based antibiotic cessation (i.e., discontinuing the antibiotic therapy once the patient's temperature falls below a certain threshold, such as $37^{\circ} \mathrm{C}$ in their case) might be sufficient for the treatment of acute cholangitis, even in cases combined with sepsis [14].

The conclusion that antibiotic therapy can safely be stopped after a short duration even in sepsis may be explained by the fact that in the case of cholangitis, 
Table 2 Data extracted on outcomes

\begin{tabular}{|c|c|c|c|c|c|c|}
\hline References & Groups & $\begin{array}{l}\text { Patient } \\
\text { number } \\
(n)\end{array}$ & Mortality $(n, \%)$ & $\begin{array}{l}\text { Recurrent } \\
\text { cholangitis } \\
(n, \%)\end{array}$ & $\begin{array}{l}\text { Duration of fever after } \\
\text { ERCP (days/hours, } \\
\text { median, range/SD) }\end{array}$ & $\begin{array}{l}\text { Length of hospitali- } \\
\text { zation (days, median, } \\
\text { IQR) }\end{array}$ \\
\hline \multirow[t]{3}{*}{ van Lent et al. [13] } & $\begin{array}{l}\text { G1: ABT for } 3 \text { days } \\
\text { or less }\end{array}$ & 41 & $6(14.6)$ & $11(26.8)$ & $1^{\mathrm{a}}\left(0-17^{\mathrm{a}, \mathrm{c}}\right)$ & \\
\hline & G2: ABT for $4-5$ days & 19 & $2(10.5)$ & $4(21.1)$ & & \\
\hline & $\begin{array}{l}\text { G3: ABT for more than } \\
5 \text { days }\end{array}$ & 20 & $1(5.0)$ & $4(20.0)$ & & \\
\hline Kogure et al. [14] & $\begin{array}{l}\text { Short ABT therapy } \\
\text { group }\end{array}$ & 18 & $0(0)$ & $0(0)$ & $2^{\mathrm{a}}$ & \\
\hline \multirow[t]{2}{*}{$\begin{array}{l}\text { Limmathurotsakul et al. } \\
\text { [15] }\end{array}$} & $\begin{array}{l}\text { G1: ABT stopped after } \\
\text { temperature below } \\
37.8 \text { degrees for } 72 \mathrm{~h}\end{array}$ & 8 & $0(0)$ & $0(0)$ & $1.8^{\mathrm{b}}\left(1.8^{\mathrm{b}, \mathrm{d}}\right)$ & \\
\hline & $\begin{array}{l}\text { G2: full } 14 \text { days of } \\
\text { ABT }\end{array}$ & 8 & $0(0)$ & $0(0)$ & $1.2^{\mathrm{b}}\left(0.7^{\mathrm{b}, \mathrm{d}}\right)$ & \\
\hline \multirow[t]{2}{*}{ Uno et al. [16] } & $\begin{array}{l}\text { G1: less than } 2 \text { weeks } \\
\text { of ABT }\end{array}$ & 51 & $0(0)$ & $0(0)$ & & $14(16-22.5)$ \\
\hline & $\begin{array}{l}\text { G2: more than } 2 \text { weeks } \\
\text { of } A B T\end{array}$ & 40 & $2(5.7)$ & $4(13.3)$ & & $17.5(10.0-17.0)$ \\
\hline
\end{tabular}

${ }^{a}$ Days

${ }^{\mathrm{b}}$ Hours

${ }^{c}$ Range

${ }^{\mathrm{d}}$ Standard deviation

bacteremia occurs due to biliary obstruction [28]. Once the source of infection is controlled (with biliary drainage), bacteremia is likely to resolve, and the patient may not need further ABT [15].

In their retrospective cohort study, Uno et al. aimed to validate an ABT duration of less than 14 days for Gramnegative bacteremia in acute cholangitis. They compared patients receiving less than 14 days of $\mathrm{ABT}$ to patients receiving $\mathrm{ABT}$ for longer. They concluded that the mortality did not significantly differ between each of the groups, and they observed fewer recurrences in the short-term antibiotic therapy group.

None of the articles included found any significant difference between short- and long-term antibiotic treatments in terms of mortality and duration of fever after the ERCP procedure. The rate of recurrent cholangitis was found to be significantly lower in the short ABT group in one article [16], and no significant difference was found in the other three. The length of hospitalization was only assessed in one study included, and a difference was found between the two groups, with significantly shorter hospitalization time in the short-term ABT group [16]. We hypothesize that the unusually long hospital stay in both groups (median of 14 and 17.5 days) in this study occurred because they only included cholangitis patients with confirmed positive blood cultures.

\section{Quality of Evidence and Quality Assessment}

Figure 2 and Table 3 show the results of the quality assessment of the studies included. With regard to the RCT (by Limmathurotsakul et al.), the Cochrane Risk of Bias Tool indicated an overall poor quality, since three points (blinding of participants and personnel; blinding of outcome assessment; and selective reporting) were evaluated as having a potentially high risk of bias (see Table 3 ).

Applying the GRADE approach to each of the outcomes assessed above resulted in a weak (2) recommendation and a very low (D) level of evidence for every outcome [12].

\section{Limitations}

During the process of conducting our systematic review, we came across several potential limitations that may impair the strength of our findings. In terms of general characteristics, the low number of articles $(n=4)$ that could be included in the final review and the low combined patient number ( $n=205$, with $n=137$ cases and $n=68$ controls) are insufficient to provide basis for strong recommendations. Moreover, only one of these studies is randomized and controlled, and it only involves 16 patients $(n=8$ cases and $n=8$ controls) [15]. We also included an article without a control (comparison, short-course ABT) group [14], and two out 
Fig. 2 Results of the Newcastle-Ottawa quality assessment scale for cohort studies

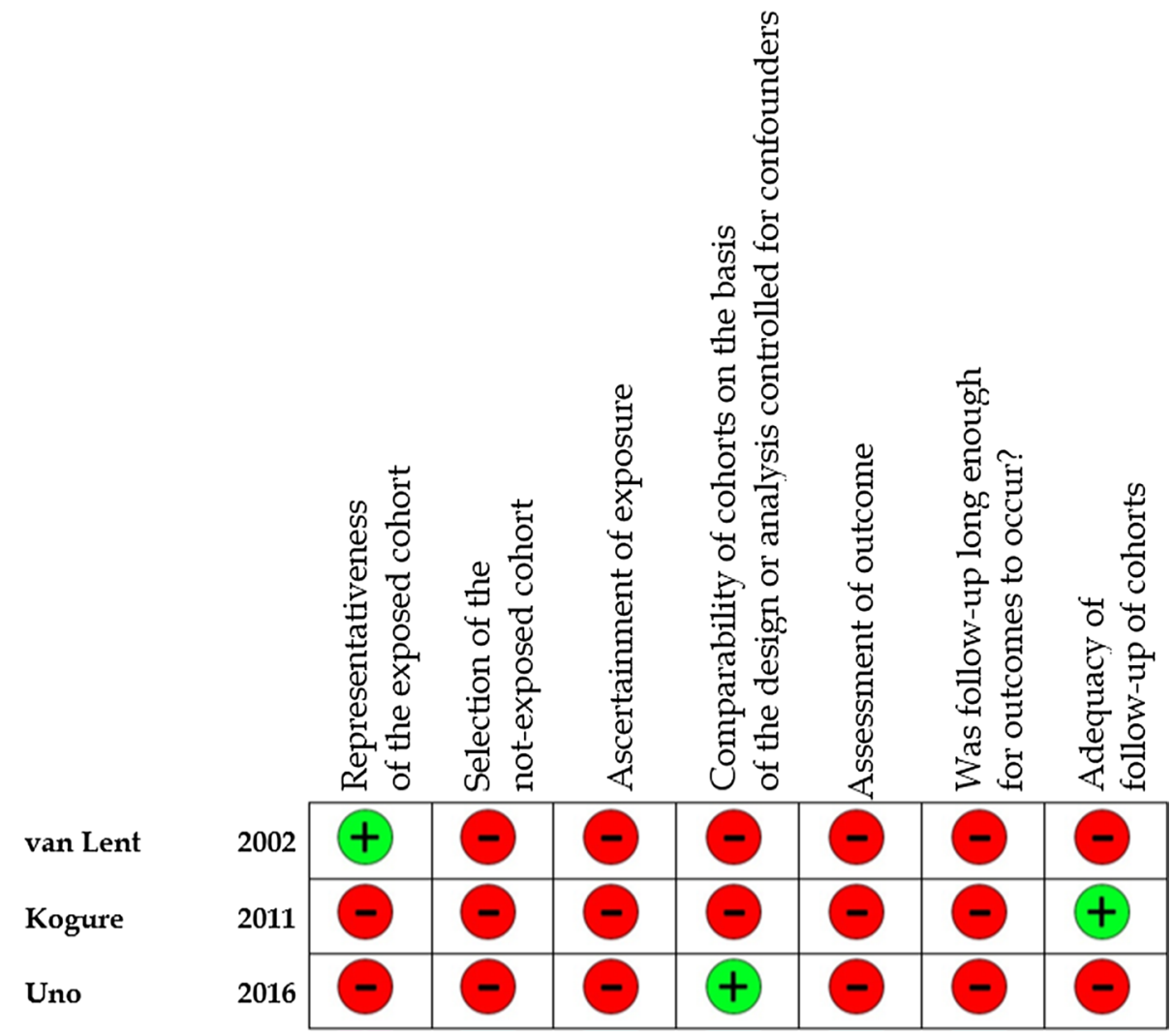

Table 3 Cochrane Risk of Bias Tool for RCTs, applied for Limmathurotsakul et al. [15]

\begin{tabular}{|c|c|c|}
\hline Entry & Judgement & Support for judgement \\
\hline Random sequence generation (selection bias) & Low risk & $\begin{array}{l}\text { Quote: "The randomization codes were generated by a computer } \\
\text { using a random mixing box" } \\
\text { Comment: Probably done }\end{array}$ \\
\hline Allocation concealment (selection bias) & Unclear risk & $\begin{array}{l}\text { Quote: "Concealed in envelops" } \\
\text { Comment: Insufficient details to allow definite judgement: Were the } \\
\text { envelops sealed and/or sequentially numbered? }\end{array}$ \\
\hline Blinding of participants and personnel (performance bias) & High risk & $\begin{array}{l}\text { Comment: No blinding mentioned in terms of allocated interven- } \\
\text { tions (the group of patients), and the lack of blinding is likely to } \\
\text { influence the outcomes }\end{array}$ \\
\hline $\begin{array}{l}\text { Blinding of outcome assessment (detection bias) (patient- } \\
\text { reported outcomes) }\end{array}$ & Unclear risk & $\begin{array}{l}\text { Quote: "The concealed randomization code was opened by an } \\
\text { investigator who was blinded to the treatment results" } \\
\text { Comment: Probably referring to the treatment results of the biliary } \\
\text { drainage and not the outcomes of the study }\end{array}$ \\
\hline Blinding of outcome assessment (detection bias) (mortality) & High risk & $\begin{array}{l}\text { Comment: No blinding mentioned in terms of outcome assessment } \\
\text { (the group of patients), and the lack of blinding is likely to influ- } \\
\text { ence the outcomes }\end{array}$ \\
\hline Incomplete outcome data addressed (attrition bias) & Low risk & $\begin{array}{l}\text { Comment: No missing outcomes reported. Probably true, especially } \\
\text { with the low patient number }\end{array}$ \\
\hline Selective reporting (reporting bias) & High risk & $\begin{array}{l}\text { Comment: An outcome listed in methods is not described in detail: } \\
\text { the overall morbidity and mortality related to acute cholangitis }\end{array}$ \\
\hline
\end{tabular}

of the four studies utilized retrospective data collection [13, 16].

In addition, the inclusion criteria were not the same in the articles. Uno et al. [16] only included cholangitis patients with positive blood culture, and there was a difference between the severities of cholangitis in the inclusion criteria across the studies analyzed. Furthermore, the type and regimen of antibiotics, as well as the definition and timing of successful biliary drainage procedures, also varied greatly. The causes of acute cholangitis were not consistent 
across the studies. For example, Limmathurotsakul et al. [15] excluded all causes except for common bile duct stones; however, the other studies were not so restrictive in terms of etiology.

With regard to the methodology in the studies, the followup period ranged from one to six months in the four studies included. This inconsistency may have an influence on outcomes, such as mortality and recurrent cholangitis rate during follow-up, especially when taking into consideration that the median time for developing recurrent cholangitis is 18 weeks after biliary drainage [27]. The criteria or reasons for the cessation of antibiotic therapy were not clearly stated in all the studies. In Kogure et al. and Limmathurotsakul et al., antibiotic treatment was stopped after the patient's temperature dropped below a certain threshold $\left(37{ }^{\circ} \mathrm{C}\right.$ and $37.8^{\circ} \mathrm{C}$, respectively) for a period of time $(24 \mathrm{~h}$ and $72 \mathrm{~h}$, respectively). Neither of these studies specifies the protocol of the temperature measurement used, and only Kogure et al. [14] provide data on the method of measurement. The other two articles contain no information on the protocol for stopping antibiotic therapy. Supplementary File 3 highlights some of the major differences between studies that contribute to the limitations of our review.

\section{Conclusions}

According to the synthesized results and conclusions from the articles included in our systematic review, short-course ABT seems adequate for the treatment of acute cholangitis once biliary drainage has been achieved. However, due to the low number of patients included, the differences in study design, and the heterogeneity of the definition used for long and short-course treatment, the quality of evidence remains very low.

In view of the conclusions of our systematic review, we believe that a new randomized controlled study is needed on the duration of antibiotic treatment in acute cholangitis to provide high-quality evidence on the topic.

This conclusion provides a foundation for a future planned RCT we plan to conduct to satisfy the need for highquality evidence.

Author's contribution EB and HP conceptualized and designed the review in conjunction with VÁ; TB, PD, and SZ constructed the search query and carried out the search process; TB, RZ, and TJ screened the articles for eligibility; TB and SL performed the data extraction; TB and $\mathrm{PB}$ conducted the quality assessment; $\mathrm{TB}$ and $\mathrm{EB}$ wrote the article; VG, RZ, and CJ supervised the study; VÁ and SZ provided valuable feedback after critically reviewing the first drafts of the manuscript. All the authors reviewed and approved the final manuscript for publication.

Funding This study was supported by an Economic Development and Innovation Operative Programme Grant (GINOP 2.3.2-15-201600048) and an Institutional Developments for Enhancing Intelligent
Specialization Grant (EFOP-3.6.2-16-2017-0006) from the Hungarian National Research, Development and Innovation Office. Funding was also received from the ÚNKP-17-3-I New National Excellence Program within Hungary's Ministry of Human Capacities.

\section{Compliance with ethical standards}

Conflict of interest The authors declare no competing interests.

Open Access This article is distributed under the terms of the Creative Commons Attribution-NonCommercial 4.0 International License (http://creativecommons.org/licenses/by-nc/4.0/), which permits any noncommercial use, distribution, and reproduction in any medium, provided you give appropriate credit to the original author(s) and the source, provide a link to the Creative Commons license, and indicate if changes were made.

\section{References}

1. Kiriyama S, Takada T, Strasberg SM, et al. TG13 guidelines for diagnosis and severity grading of acute cholangitis (with videos). J Hepatobiliary Pancreat Sci. 2013;20:24-34.

2. Gomi H, Solomkin JS, Schlossberg D, et al. Tokyo Guidelines 2018: antimicrobial therapy for acute cholangitis and cholecystitis. J Hepatobiliary Pancreat Sci. 2018;25:3-16.

3. Miura F, Takada T, Kawarada Y, et al. Flowcharts for the diagnosis and treatment of acute cholangitis and cholecystitis: Tokyo Guidelines. J Hepatobiliary Pancreat Surg. 2007;14:27-34.

4. Gomi H, Solomkin JS, Takada T, et al. TG13 antimicrobial therapy for acute cholangitis and cholecystitis. J Hepato-BiliaryPancreat Sci. 2013;20:60-70.

5. Dumonceau JM, Tringali A, Blero D, et al. Biliary stenting: indications, choice of stents and results: European Society of Gastrointestinal Endoscopy (ESGE) clinical guideline. Endoscopy. 2012;44:277-298.

6. Adler DG, Baron TH, Davila RE, et al. ASGE guideline: the role of ERCP in diseases of the biliary tract and the pancreas. Gastrointest Endosc. 2005;62:1-8.

7. Tan M, Schaffalitzky de Muckadell OB, Laursen SB. Association between early ERCP and mortality in patients with acute cholangitis. Gastrointest Endosc. 2018;87:185-192.

8. Boey JH, Way LW. Acute cholangitis. Ann Surg. 1980;191:264-270.

9. Moher D, Liberati A, Tetzlaff J, Altman DG, Group P. Preferred reporting items for systematic reviews and meta-analyses: the PRISMA statement. BMJ. 2009;339:b2535.

10. Lo CK, Mertz D, Loeb M. Newcastle-Ottawa Scale: comparing reviewers' to authors' assessments. BMC Med Res Methodol. 2014; $14: 45$.

11. Yang ZR, Sun F, Zhan SY. Risk on bias assessment: (2) Revised Cochrane risk of bias tool for individually randomized, parallel group trials (RoB2.0). Zhonghua Liu Xing Bing Xue Za Zhi. 2017;38:1285-1291.

12. Guyatt GH, Oxman AD, Vist GE, et al. GRADE: an emerging consensus on rating quality of evidence and strength of recommendations. BMJ. 2008;336:924-926.

13. van Lent AU, Bartelsman JF, Tytgat GN, Speelman P, Prins JM. Duration of antibiotic therapy for cholangitis after successful endoscopic drainage of the biliary tract. Gastrointest Endosc. 2002;55:518-522. 
14. Kogure H, Tsujino T, Yamamoto K, et al. Fever-based antibiotic therapy for acute cholangitis following successful endoscopic biliary drainage. J Gastroenterol. 2011;46:1411-1417.

15. Limmathurotsakul D, Netinatsunton N, Attasaranya S, Ovartlarnporn B. An open-labeled, randomized controlled trial comparing between short duration and standard 14 days antibiotic treatments for acute cholangitis in patients with common bile duct stone after successful endoscopic biliary drainage. A preliminary report. Gastrointest Endosc. 2014;79:AB251.

16. Uno S, Hase R, Kobayashi M, et al. Short-course antimicrobial treatment for acute cholangitis with Gram-negative bacillary bacteremia. Int J Infect Dis. 2017;55:81-85.

17. Wu AHW, Lee SW, Lam SH, Kwok SPY, Lai WM. Cefepime in the treatment of acute cholangitis 2001. pp. 32-37.

18. Sawyer RG, Claridge JA, Nathens AB, et al. Trial of short-course antimicrobial therapy for intraabdominal infection. $N$ Engl J Med. 2015;372:1996-2005.

19. Llewelyn MJ, Fitzpatrick JM, Darwin E, et al. The antibiotic course has had its day. BMJ. 2017;358:j3418.

20. Costelloe C, Metcalfe C, Lovering A, Mant D, Hay AD. Effect of antibiotic prescribing in primary care on antimicrobial resistance in individual patients: systematic review and meta-analysis. $B M J$. 2010;340:c2096.

21. Nasiri MJ, Goudarzi M, Hajikhani B, Ghazi M, Goudarzi H, Pouriran R. Clostridium difficile infection in hospitalized patients with antibiotic-associated diarrhea: a systematic review and metaanalysis. Anaerobe. 2018;50:32-37.

22. Heit JA, Melton LJ 3rd, Lohse CM, et al. Incidence of venous thromboembolism in hospitalized patients vs community residents. Mayo Clin Proc. 2001;76:1102-1110.

23. Welch C, Hassan-Smith ZK, Greig CA, Lord JM, Jackson A. Acute sarcopenia secondary to hospitalisation-an emerging condition affecting older adults. Aging Dis. 2018;9:151-164.

24. Zhong DC. Biliogenic liver abscess caused by acute obstructive suppurative cholangitis. Zhonghua Wai Ke Za Zhi. 1992;30:8890, 124-125.

25. Boender J, Nix GA, de Ridder MA, et al. Endoscopic sphincterotomy and biliary drainage in patients with cholangitis due to common bile duct stones. Am J Gastroenterol. 1995;90:233-238.

26. Sugiyama M, Atomi Y. Treatment of acute cholangitis due to choledocholithiasis in elderly and younger patients. Arch Surg. 1997;132:1129-1133.

27. Chopra KB, Peters RA, O'Toole PA, et al. Randomised study of endoscopic biliary endoprosthesis versus duct clearance for bileduct stones in high-risk patients. Lancet. 1996;348:791-793.

28. Lipsett PA, Pitt HA. Acute cholangitis. Surg Clin North Am. 1990;70:1297-1312.

\section{Affiliations}

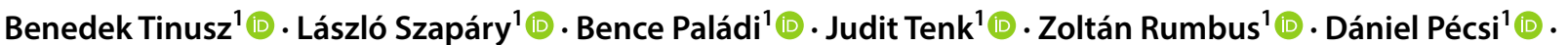

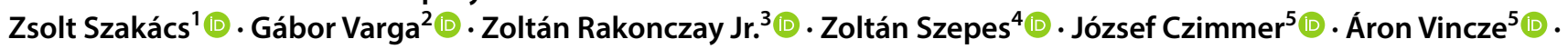 Péter Hegyi ${ }^{1}$ [ $\cdot$ Bálint Erőss ${ }^{1}$}

Benedek Tinusz

tinuszben@gmail.com

László Szapáry

lacika.szapary0701@gmail.com

Bence Paládi

pbence0720@gmail.com

Judit Tenk

judit.tenk89@gmail.com

Zoltán Rumbus

rumbuszoltan@gmail.com

Dániel Pécsi

daniel.pecsi1991@gmail.com

Zsolt Szakács

szaki92@gmail.com

Gábor Varga

varga.gabor@dent.semmelweis-univ.hu

Zoltán Rakonczay Jr.

rakonczay.zoltan@med.u-szeged.hu

Zoltán Szepes

szepes.zoltan@med.u-szeged.hu
József Czimmer

czimmer.jozsef@pte.hu

Áron Vincze

vincze.aron@pte.hu

Péter Hegyi

hegyi2009@gmail.com

1 Institute for Translational Medicine, Medical School, University of Pécs, Szigeti út 12, Pecs 7624, Hungary

2 Department of Oral Biology, Faculty of Dentistry, Semmelweis University, Budapest 1085, Hungary

3 Department of Pathophysiology, Medical School, University of Szeged, Szeged 6720, Hungary

4 First Department of Medicine, University of Szeged, Szeged 6720, Hungary

5 Department of Gastroenterology, First Department of Medicine, Medical School, University of Pécs, Pecs 7624, Hungary 